\title{
A Dynamic Healthcare Portal Design and Enhancements
}

\author{
Yung-Ching Weng ${ }^{1}$, Sheau-Ling Hsieh², Kai-Ping Hsu' ${ }^{1}$, Chi-Huang Chen"1, \\ Po Hsun Cheng ${ }^{3}$ and Feipei Lai ${ }^{1}$ \\ ${ }^{1}$ National Taiwan University, ${ }^{2}$ National Chiao Tung University, \\ ${ }^{3}$ National Kaohsiung Normal University \\ Taiwan
}

\section{Introduction}

National Taiwan University Hospital (NTUH) is a large scale healthcare centre and has been operating over hundred years. Currently, it includes different generations of Healthcare Information Systems (HIS); there are over 30 major independent systems in NTUH. These systems consist of clinical information applications focusing on patient cares, pharmacy, laboratory and radiology systems, administrative facilities, financial systems, resource management, claims processing, etc. The portal is an essential entity to integrate, glue these systems, platforms together. An effective, convenient as well as user friendly portal can provide adequate information for NTUH staff, medical practitioners' daily operations. Moreover, a Single Sign on Service (SSOS) design is crucial to unify, simplify various systems log-on processing.

As NTUH users' requirements increase rapidly, the number of menu selections, i.e., applications or function linkages, grows exponentially. The scrollable extension menu, implemented in the previous portal, is not spatial, temporal sufficiently and efficiently. The maintainability of menu items is hampered under the situation. Furthermore, in general, a user normally accesses not more than 10 function selections. In order to trace individual behaviours for frequently executed functions, a logging scheme, containing a list of actions, is proposed. Assistive web technologies for persons with disabilities are initiated. Therefore, to improve the NTUH portal, we explore and launch a new one to achieve the targets.

\section{Background \& Related Work}

\subsection{Background}

National Taiwan University Hospital (NTUH) was established in 1895. There are approximate 8,000 outpatients, 300 emergency cases, daily on average, and around 2,200 beds for inpatients. The NTUH portal is the main entrance to various aggregated systems supporting operations for NTUH staffs, physicians as well as educational purposes. The portal provides essential directions for users to browse over NTUH Intranet behind the firewalls. It involves extensible difficulties: 
1) There are over 30, rapidly increasing, major independent systems in NTUH. The systems encompass many resources; it becomes cumbersome for medical staff to authenticate every time while attempting to access a new resource. The legacy or previous portal did not support SSOS. Users need to keep separate identifications, passwords to execute different systems individually.

In addition, the multiple login processes disturb medical staffs. It also generates resistances and causes the system's usage downgrade or undesirable. There were cases that doctors avoid the login process, and simply provide usernames, passwords to the assistants and ask them to operate directly. The situation raises security concerns regarding the correctness of patient's records and data entered. Later, it may generate threats to patient's health or life. A Single Sign-On facility is a must.

2) The previous portal main page contains scrollable extension menu (Weng et al., 2007; Goodman, 2003) to support function linkages. As NTUH users' operation demands increase, the number of linkages, steady increments, is over 300 currently. The scrollable menu is not spatial sufficiently, well organized. Thus, the menu utilization is not convenient.

3) The existing portal has been implemented at server side ASP scripting technologies. Any ASP page modification only requires uploading onto web servers for menu deployment. However, the newly designed portal is implemented in ASP.NET with C\# programming language. $\mathrm{C \#}$ is a compiling language. If any menu altered, the server side programs have to be re-compiled and re-deployed. The menu modification efforts increase significantly. Therefore, more efficient approaches ought to be brought up and enhanced under the new environment.

4) Because of lacking maintenance, the legacy portal contains failure links as well as redundant entrances in the previous scrollable extension menu.

\subsection{Related Work}

\subsubsection{Web portal system}

The web portal services have turned into an imperative part of human life. The portal is an environment through which a user can gain access to web-based information and tools from a single Internet location (Brakel, 2003; Mary, 2002; Tsai et al., 2005; Zhu et al., 2004). Early clinical systems attempted to provide the functionality envisioned by the computer-based patient records, but were hampered by incompatible standards and a lack of interconnectivity (Fraser et al., 1997; McDonald et al., 1998). With the development of the web portal services, almost every large system vendor is now offering a web-based clinical system (Shepherd, 2000). In particular, consumers of health care are demanding easy access to relevant health information (Lee et al., 2007; Raghupathi, 1997; Zirpins et al., 2001).

A web portal is built upon layers of services and component modules (Azar et al., 2008; Freudenstein et al., 2006; Murray, 2002; Murray, 2003; Oo, 2006). The framework must facilitate the integration of a wide range of data, provide efficient access to relevant content, and incorporate the ability to organize materials that employees routinely operate.

There is no definitive categorization of the types of web portals (Azar et al., 2008). Strauss (Strauss, 2002) categorizes web portals into "Horizontal Enterprise Portals" and "Vertical Enterprise Portals". The classification of horizontal and vertical portals is the most commonly used and understood method (Tsai et al., 2005; Brakel, 2003; Zirpins et al., 2001; 
Amor, 1999). In general, portals are in layered, web, architectures (Murray, 2002; Freudenstein et al., 2006; Murray, 2003).

Murray (Murray, 2002) defined that a healthcare portal strategy is comprised of six layers. To accomplish these, each layer addresses its primary functionalities. For examples, in the Security layer, a single sign on environment for all users is the basis of providing a single point of entrance (Russler et al., 2001; Hsieh et al., 2006). The Enterprise Application Integration layer provides the ability to exchange and integrate data among applications via open standards, e.g. eXtensible Markup Language (XML) (Freudenstein et al., 2006; Murray, 2003).

In addition, the web-based applications are designed to be modular and built on a distributed, n-tier architecture. The middle tier seamlessly connects the front end, webbased browsers, to the back end servers, or applications (Shepherd, 2000; Oo, 2006). Overtime, new business applications and capabilities can simply be added to existing resources within the highly extensible architecture (Yang et al., 2006). The ability of identifying and extracting pertinent information in an efficient manner is paramount. Moreover, the portal should be programmable and flexible so that the information can be dynamically selected from various sources (Trippe, 2001). The ability to exchange data among applications and provide application integration enterprise-wide is a fundamental component of a successful web portal (Rosen, 2000; Rudenstien, 2000). Within healthcare, the Health Level Seven (HL7) standard defines the format and protocol of messages that are exchanged among healthcare applications. It enables systems to create XML documents that incorporate HL7 message content (Shepherd, 2000; Arbor, 2000).

\subsubsection{Service oriented architecture}

A Service Oriented Architecture (SOA) represents the current pinnacle of interoperability, in which resources on a network are available as individual, loosely-coupled and independent services (Freudenstein et al., 2006; Murray, 2003; Bunge et al., 2008; Lewis et al., 2007). As Service-oriented Architecture (SOA) matures, an efficient approach for the integration of web services in portals is required. SOA is a desirable and inevitable solution.

In summary, a successful portal includes determining factors: 1) architecture built on layers of services and component modules; 2) providing the ability to inter-mingled data and content from multiple sources stored in multiple formats; 3 ) a framework that is extensible by employing open standards in the development of portal services (Mary, 2002; Brakel, 2003; Azar et al., 2008).

\subsubsection{Single sign-on approach}

Single sign-on is a simple means of managing passwords and authenticating users to various applications. It allows users to access all authorized services and resources seamlessly (Adabala et al., 2004; Heckle et al., 2008; Volchkov, 2001; Heckle, 2007; Mauro, 2008). However, its implementation has tremendous complexities that involve overall security policies, user profiles, natures of business, integration of legacy, web applications portfolios, cost structures of Information Technology operations, as well as future application development strategies (Heckle et al., 2008; Volchkov, 2001).

In general, pragmatic approaches adopt the following criteria: 1) modifying existing applications and building new ones, synchronizing passwords to share recourses and 
services; 2) establishing external tools or an authentication middleware, layer to support authentication methods or servers; 3) configuring legacy applications with their existing directories and synchronizing with the enterprise directory, central administration promptly; 4) delegating or mapping user credentials or capabilities on resources; 5) developing trust channels to deliver, share user credentials information (Adabala et al., 2004; Heckle et al., 2008; Volchkov, 2001; Heckle, 2007). In addition, the single sign-on technology can mitigate the shortcomings of id/password approaches.

\subsubsection{Web resources monitoring}

The web servers record their visitors' behaviours, e.g., handling the resource requests from clients in log files; statistical analyses of these files can provide measurements on total page acquired, referrals, visitors' uniqueness, as well as requested resource types (Bracke, 2002 ; Anamarija et al., 2002). In addition, the logging services and analyses have been adopted in a few healthcare and bioscience websites to determine the usefulness of online resources. Furthermore, the system evaluation can enhance the online health sciences to conform to the healthcare practitioners needs as well as to identify patient-specific information (Liu et al., 2006). The techniques can assist administrators to evaluate websites, analyze resource usages, justify the resource priorities, and improve websites design (Rowbottom et al., 2005; Chen \& Cimino, 2003; Chen \& Cimino, 2004).

\subsubsection{Site map}

Numerous design and usability guidelines suggested that a site map is necessary for every web site (Farkas \& Farkas, 2000; Nielson, 2002). A well designed site map mirrors its associated web site contents, link structures accordingly. It can alleviate users' bewilderment during web navigating (Bernard, 1999), to understand an overview of a site topology, and to search for required information quickly and accurately (Dieberger, 1997; Kim \& Hirtle, 1995; Li et al., 2001). In principle, the criteria for prominent large web site maps can be summarized as: 1) capable of covering the contents of Web sites; 2) capable of supporting navigation via visualized Web site topologies; 3 ) flexible to illustrate or render the web contents and link structures imposing hidden or flatten descriptions, i.e., with multiple granularity of details or topic-focused; 4) enabling site maps construction automatically ( $\mathrm{Li}$ et al., 2001; Yip, 2004; Inder et al., 1998; Danielson, 2002). In addition, Li, Ayan, and et al. (Li et al., 2001) identify the site maps must be informative and representative indicated by citation analyses.

Although doctors can be slow adapters of new information technology (Tsai et al., 2005; Cheng et al., 2004), the availability of any data, at any time, from any place, changes the healthcare infrastructures dynamically via web portal.

\section{Design Objectives \& Requirements}

According to the problems described in the Background, we design a new portal to solve them. Planning for the portal implementation should be seen as a process of building an infrastructure, foundation for the future, not as developing of a single all-encompassing solution. Therefore, the new portal has to satisfy the requirements as listed: 
1) The new portal demands integrating the interface of multi-system authentication and authorization, i.e., Single Sign on Service (SSOS) interface. It validates user's authentication as well as access control capabilities. The capabilities are visualized in menu selections based upon user's authorization. If a user has no authority to access certain functions, the selections will be invisible.

2) The new portal main page ought to be well organized and hierarchical. It needs cover over 300 menu selections for clinicians and administrative staff usages. The selections provide function linkages to HIS (Outpatient, Inpatient, and Emergency Information Systems (Ko et al., 2006)), Healthcare Supporting Services (Critical Healthcare Alerts, Medical Report Review Services, and Consultation Services), Administrative Information System (Human Resources, Medicine Inventory, and Accounting), as well as others. Therefore, a hierarchical, drop-down navigation menu system architecture is inevitable.

3) The function linkages vary frequently; a dynamic menu configuration and generation must be manipulated effectively and efficiently.

4) The portal supports two bulletin boards in one web page, one for HIS, the other for administrative purpose. Furthermore, the boards require supporting real time, on-line features.

5) Because of the large numbers of linkages, the performance of main page rendering is concerned.

6) At present, NTUH HIS is under developing. The portal acquires to correctly redirect to developing, testing, or on-line production servers instantaneously.

\section{System description \& implementation}

After requirement analyses, NTUH HIS has been developed, deployed based upon the middleware multi-tier infrastructure, Service-Oriented Architecture (SOA) technologies (Papazoglou, 2003; Papazoglou \& Heuvel, 2007), i.e., Web Services (Krafzig et al., 2005; Shepherd et al., 2000) .NET. SOA represents the current pinnacle of interoperability, in which HIS resources distributed over networks are available as individual, loosely-coupled and independent services (Freudenstein et al., 2007; Murray, 2003; Bunge et al., 2008; Lewis et al., 2007). SOA is a desirable and inevitable solution to integrate diverse platforms, database as well as further merging, extending into NTUH HIS. The overall NTUH HIS frameworks are depicted in Figure 1. Within the diagram, individual components are described as followings.

\subsection{Overall architecture}

In Figure 1, it contains three major components, i.e., the front-end module, the middleware module, and the back-end services including database servers. The front-end module handles user interfaces via browsers. It establishes the user sessions as well as provides services to validate users' authentications, authorizations. The middleware module, i.e., HL7 Middleware Framework as indicated in the diagram, glues the front-end services and the back-end facilities together. It provides communication and connectivity via SOA (Web Services) mechanism. The HL7 embedded XML formatted data is implemented in the framework for data exchanges among the modules. The back-end facilities support services and database storage. 
Further detailed illustrations of the individual modules are provided as followings. In the front-end module, for user friendly browsing interfaces, we adopt web based services. The Portal Servers support the login process with the Single Sign on Service (SSOS) features (Cheng et al., 2004). The servers construct dynamic web URL linkages (Weng et al., 2007), direct to HIS components in the architecture. To enable the SSOS features, the authentication and authorization component (Auth-WS) is introduced. During the HIS operations, any validation needs to be verified through the Auth-WS. The Auth-WS integrates the Websession Servers and Win-session Servers. The Web-session Servers interact with all other servers in the architecture under the .NET web services environment. The Win-session Servers are implemented as daemons (Window Services). All established conversations, sessions are executed by the daemons including database access.

The Web User Interface (WebUI) Servers generate web-based pages for users' interactive activities. The State-session Servers store the user's web session status variables for analyzing user logic and validation.

In the middleware module, the ancillary Sub-systems provide the connectivity between the WebUI Servers and HIS database (HIS DB) for HIS applications. The messages communicated between the Sub-systems and WebUI Servers are exchanged via the HL7 Framework (Ko et al., 2006). The HL7 Framework is the Middleware Integration Engine of the HIS architecture. It supports message management, routing, mapping, and database access. Detailed information about the processing of each message is also automatically logged by the Engine. Moreover, the Engine glues the medical systems (or applications) together. The HL7 Middleware accesses HL7 message, embedded in XML format, over Simple Object Access Protocol (SOAP). (Yang et al., 2006; Phan et al., 2007; HL7 Standard v2.5, 2003) 


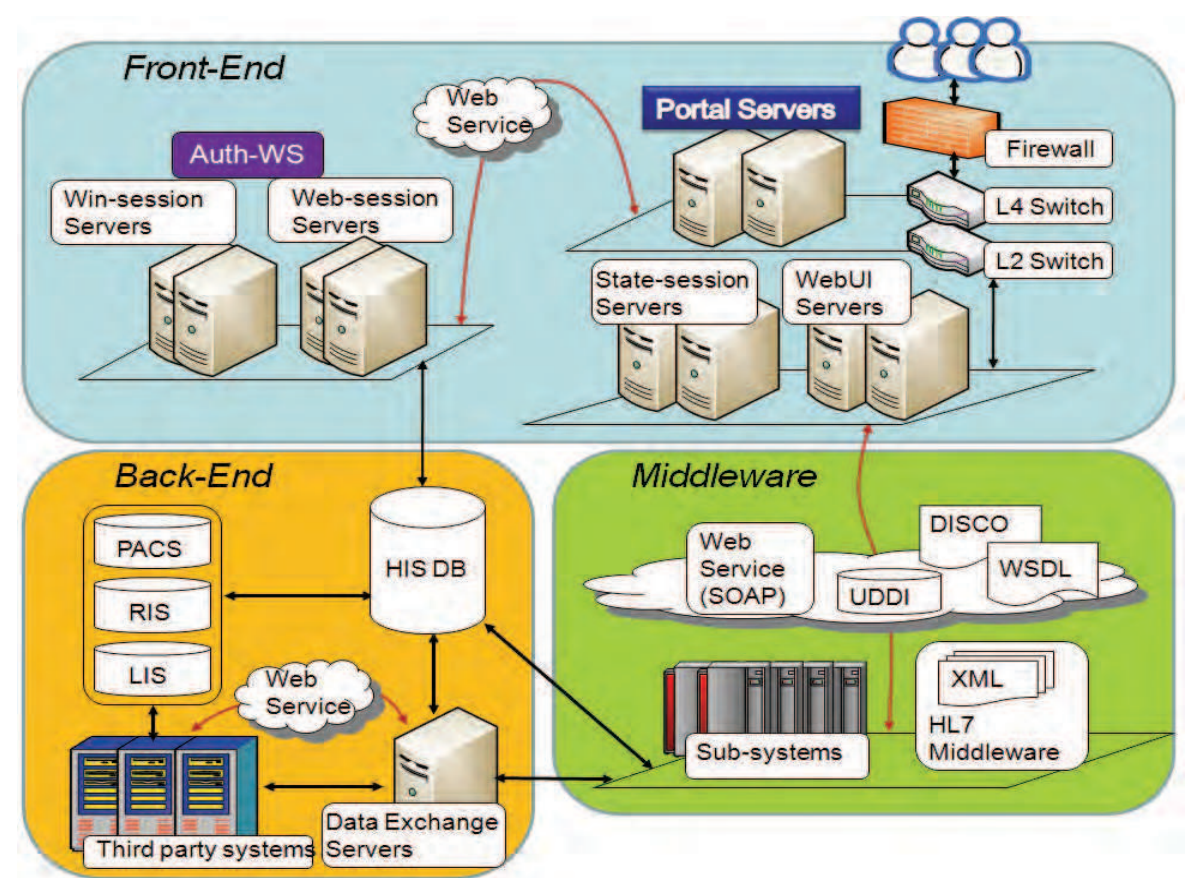

Fig. 1. NTUH HIS overall architecture

In order to achieve the data consistency, we introduce a Data Exchange Server that only receives the message sending from the HL7 Middleware. While Data Exchange server receiving messages, it will perform the data synchronization among patient demographic data in HIS, patient radiology information orders to Outsourcing Systems, i.e., RIS (Radiology Information System) database, or laboratory orders to LIS (Laboratory Information System), i.e. Legacy HIS, database. This data exchange processing can ensure all data in the systems, i.e., HIS and Outsourcing Systems, are updated and consistent as indicated in the back-end facilities (Hsieh et al., 2006; Hsieh et al., 2007; Weng et al., 2006).

To increase the performance of the NTUH HIS, a cluster of identical servers are deployed and dispatched dynamically by introducing Layer 4 and Layer 2 Switches. All the servers are configured running under load balancing as well as failover modes to ensure the system's availability and concurrency. The firewalls are also installed to enhance the security of the architecture.

\subsection{Redirect scheme \& Single sign on service}

\subsubsection{Redirect scheme}

NTUH HIS is a newly developed system (Hsieh et al., 2007; Ko et al., 2006; Yang et al., 2006). It supports multiple execution environments, i.e., developing, testing, as well as on-line production. Every environment is a complete HIS framework. For example, it includes Portal Server, Auth-WS (Web-session Server \& Win-session Server), WebUI Server and 
State-session Server (i.e., Application Server), Sub-system, as well as Database Server (shown in Figure 2). The servers are configured in clusters as described in the "Overall architecture" Section. However, in each environment, the numbers of the identical servers are varied in clusters. To ensure practitioners as well as patients privacies, the databases in developing and testing environments are scrambled.

In the developing environment, initially the HIS engineers implement modules, functionalities locally and individually. Afterwards, the integrated modules are verified through regression tests. Secondly, the software installs and deploys under the testing environment for fully evaluations. At last, the products, including Legacy HIS and Outsourcing Systems, are executed and running under the real, on-line environment for daily activities. Switching among different environments is implemented via the usage of Windows registry mechanism. Therefore, the portal can correctly redirect to developing, testing, or on-line production servers spontaneously.

\subsubsection{Single sign on service}

\subsubsection{Single sign on components}

The concept and the essence of Single Sign-On scenario have been addressed above. Users can login the portal from NTUH Intranet behind the firewalls. Currently, the implementations of the SSOS scheme contain Portal Servers, Auth-WS servers, and Application Servers: e.g. HIS components, Legacy HIS, as well as Outsourcing Systems, as shown in Figure 2. The servers are configured, in clusters, running under load balancing, fault tolerance mode.

The Portal Servers consolidate the SSOS, as illustrated in Figure 2 blue arrows, and deliver users' identities to the Auth-WS servers as indicated in red arrows. The Auth-WS validates user's authentication, authorization and generates an authentication access key for the user. The Web-session Servers and Win-session Servers execute together to provide the Auth-WS functionalities. During verifications, the Web-session Servers interact with all other servers, i.e., Portal Servers, HIS components, Legacy HIS, Outsourcing Systems (depicted in red arrows) to achieve the SSOS scheme. After SSOS validation, via Portal Server, other servers can be invoked subsequently, eventually connected to the HIS databases if required. 


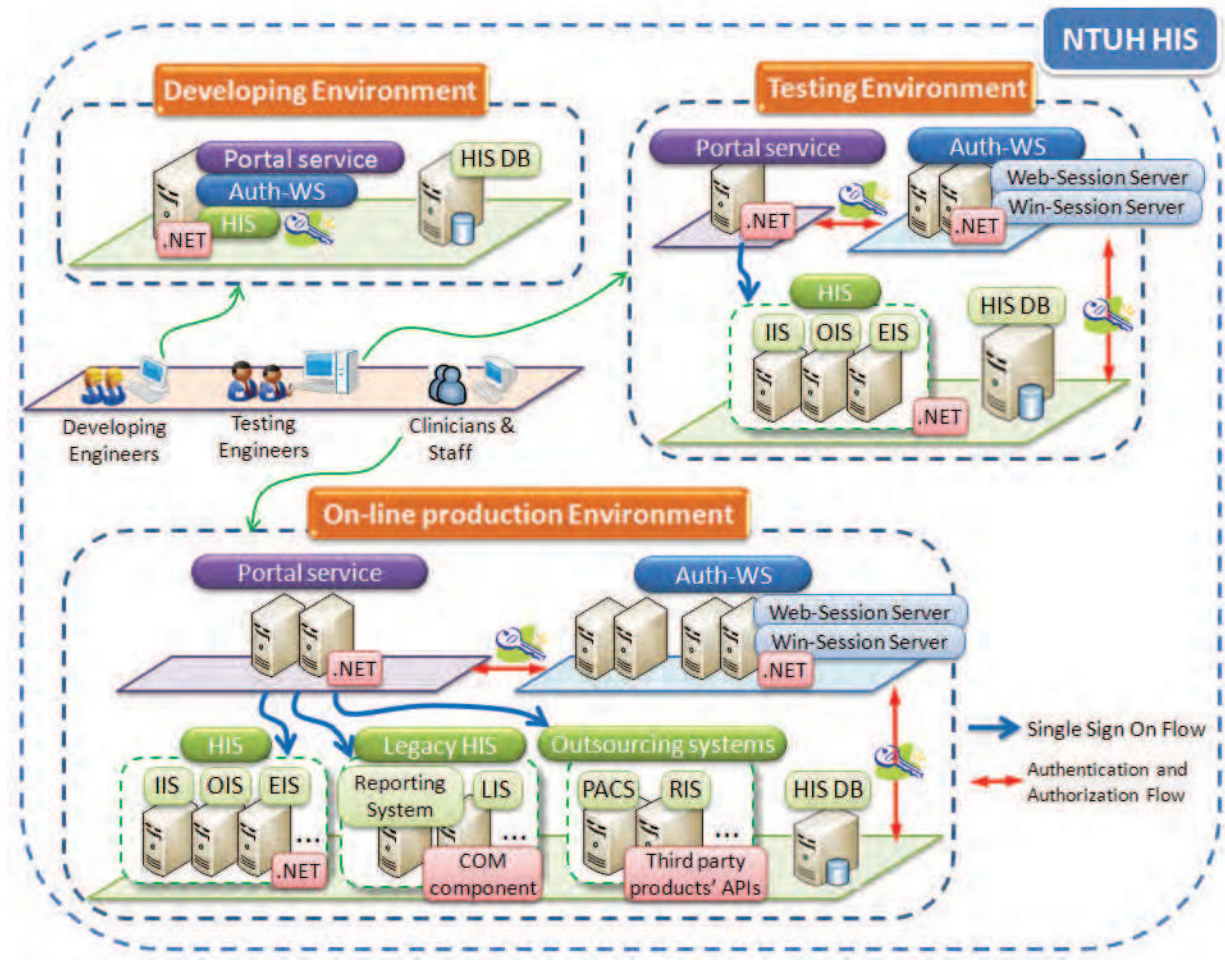

Fig. 2. NTUH Single Sign On scheme \& execution environment

\subsubsection{Single sign on approaches}

NTUH is a large enterprise having the ramifications of roles and access permissions. For growing diversity, complexities of acute hospital care, it is particularly difficult to achieve, predict clearly mapping medical providers into roles or assigning access permissions, privileges to roles in healthcare environments. Initially, the hospital adopts the classical role based access control mechanism to deal with users, roles, and associated access rights (Barkley, 1997; 2004-Single). However, we encounter a dilemma: either few roles defined inducing role expansion (Adamcik et al., 1986; Bullough, 1976) or a role per individual resulting in role proliferation (Zhang, 2003; Woods, 2007). Therefore, to cope with the conflicts, a NTUH employee is entitled a basic set of permissions, following the principle of least privilege, according to his/her occupational territory. Additional access permissions, authorities will be aggrandized on demand. In here, the access permissions are pre-defined as web page access rights.

The SSOS scheme has been implemented as followings. For authentication, user's employee ID, SSN (Social Security Number), and current timestamp are utilized to randomly generate the authentication access key. The key is utilized to authenticate among the NTUH components to achieve the SSOS scheme as described in the previous section. For authorization or access permissions, each HIS web page is assigned an identity, i.e., a web 
page ID; every user is correlated with a set of web pages. If a user does not have the authority, the user can not access, execute the web pages. The user ID and his/her associated web page IDs are stored and maintained in the HIS database. In addition, prefetched, paired page ID \& user ID can be cached in Win-Session Server in order to improve the validation performance. The cached data are synchronized with HIS database on hourly basis.

The architecture of Web-session Servers is developed, deployed under the .NET web services environment. The Win-session Servers are implemented as daemons. All requests received in the Web-session Servers are forwarded to the daemons and operated there, including database interfaces.

Auth-WS is the core of the SSOS scheme for certifications. In the scheme, the Portal service and HIS components are developed under Microsoft .Net technologies. Thus, these two modules can communicate with Auth-WS directly. However, we design a COM component to adopt, facilitate the communications between the Legacy HIS applications and the AuthWS. The communications between the Auth-WS and the Outsourcing Systems are achieved via their APIs. The flows of the scheme are demonstrated in Figure 2 red arrows.

\subsection{Portal design \& implementation}

In order to achieve the requirements, we design and enhance a new, dynamic portal for NTUH. First, the portal integrates SSOS features. Secondly, we establish a hierarchical architecture and classify function linkages into groups which will be described clearly later. Therefore, the portal can provide intuitive and effective access. In addition, the portal site needs to provide visualized menu selections. The independent function linkages (URL links) are kept in files, i.e., configuration files. These files will be used for menu configuration and generation dynamically.

\subsubsection{Classification of function linkages}

In NTUH, the number of function linkages is numerous, over 300. Moreover, in the previous portal, the links are not classified. It is not easy to scroll and select the target links. After reviewing existing function links, we classify 7 groups and establish a hierarchical, dropdown navigation menu as shown at top row of Figure 3. Each sub-tree or branch of the hierarchical classification rooted at the portal represents a major subject area such as clinical care, patient care, health services administration, research, and teaching. In here, the groups are categorized into: HIS, Healthcare Supporting Services (HSS), Administrative Information System (AIS), Digital Learning (DL), Information Security (IS), Personal Data Management (PDM), and Other Resources (OR).

HIS and HSS involve most healthcare associated services. In HIS, it includes the major healthcare information services, e.g., Registration, Ward, Laboratory, Pathology, Pharmacy, and Billing. Medical Report Review Services, Critical Healthcare Alerts, and IC card tools are classified in the HSS group. The AIS consists of Human Resources, Accounting, and Medicine Inventory. The DL contains: educational instructions, discussion forums, questionnaires, as well as on-line exams. Secured, classified documents and materials are stored in IS. It provides privacy and security. Users' personal information functions are maintained in PDM group. These functions include personal password, e-mails, and control access. Finally, the other administrative information is preserved in OR group, e.g., 
individual department home pages as well as announcements. Based on the classification, the NTUH users can operate the portal intuitively and effectively.

\begin{tabular}{|c|c|c|c|c|c|}
\hline 㙏潦系統 & 䣵源支援 & \multicolumn{2}{|r|}{ 其他筫源 } & \multicolumn{2}{|c|}{ 數优學習 } \\
\hline & 院長室 & b & & & \\
\hline & IC卡工其 & & & & \\
\hline & 緊急通報系統 & & & & \\
\hline & 影像維護系統 & & & & \\
\hline & 報告查詢系統 & 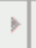 & 住院報告 & $b$ & \\
\hline & 檢查說明書及呼吸照應 & $b$ & 檢驗報告 & $b$ & 撿醫部䖯告告 \\
\hline & 詢問台 & $b$ & 綜合診療部報告 & $\rightarrow$ & 撿驗正常值 \\
\hline & 照會系統 & $\Rightarrow$ & 小兒超音波報告 & b & 累積報告 \\
\hline & 急診 & b & 神經部檢查報告 & $b$ & 子宮頚抹片 \\
\hline & 品管中心 & 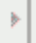 & 內科部報告 & $b$ & \\
\hline & 臨床試驗案件管理系統 & & 基因陾學部檢查幸 & $\rightarrow 1$ & \\
\hline
\end{tabular}

Fig. 3. Hierarchical drop-down navigation menus

\subsubsection{Access control capability}

The portal provides the menu access control. It means if a user has no right to operate a function, the application link is not visible. For example, administrative staffs cannot execute the Medical Report Review Services in the HSS group; the service links are not visible to them. This capability is implemented in configuration files. There is a "check" property for every menu selection item in the files. The property can control the visibility of menu linkage. This feature will be discussed in details in the "Content of configuration file" Section.

\subsubsection{DDNM design \& implementation}

NTUH portal site is designed as hierarchical, drop-down navigation menus (DDNM) (Goodman, 2003), depicted in Figure 3. The web page only displays in groups initially. Users first select a group; all the function linkages in the group will be rendered. This approach makes space usage flexibly as well as enlarges the amount of function linkages effectively.

Hierarchical DDNM is a client side display mechanism, i.e., this feature executes on user local machine by web browser. JavaScript is a powerful scripting language running in client browser, and it has been supported by many websites. Therefore, we choose JavaScript to implement the client side hierarchical DDNM.

Although the hierarchical DDNM solves the spatial problem of displaying a huge amount of function linkages (URL links), we quickly face another challenge. Because scripts are executed at client side, the URL link is normally hard coded in the scripts. Any URL link modification will cause the server side programs be revised. In addition, if the server side language is a compiling language, i.e., ASP.NET with C\# programming language, the 
program needs to be re-compiled and re-deployed. Therefore, the modification of URL link is time consuming. In order to solve the problem, the URL link should be retrieved at server side dynamically and not hard coded in scripts.

At beginning, the server side program retrieves URL links from the configuration files stored in the servers. A complete DDNM web page embedded with JavaScript is dynamically generated by the server. Afterwards, the client browser executes the scripts and displays the hierarchical DDNM. Figure 4 illustrates the concepts of dynamic, hierarchical DDNM. In the diagram, the users initiate requests; according to the selections, the web server retrieves the associated configuration files and generates the corresponding web pages, delivers them to the client side. The browsers render the web page and display the DDNM. Therefore, if the URL links need to be changed, we only modify the contents of configuration files. The server side program is independent from URL links. Thus, the URL links variation cost reduces significantly.

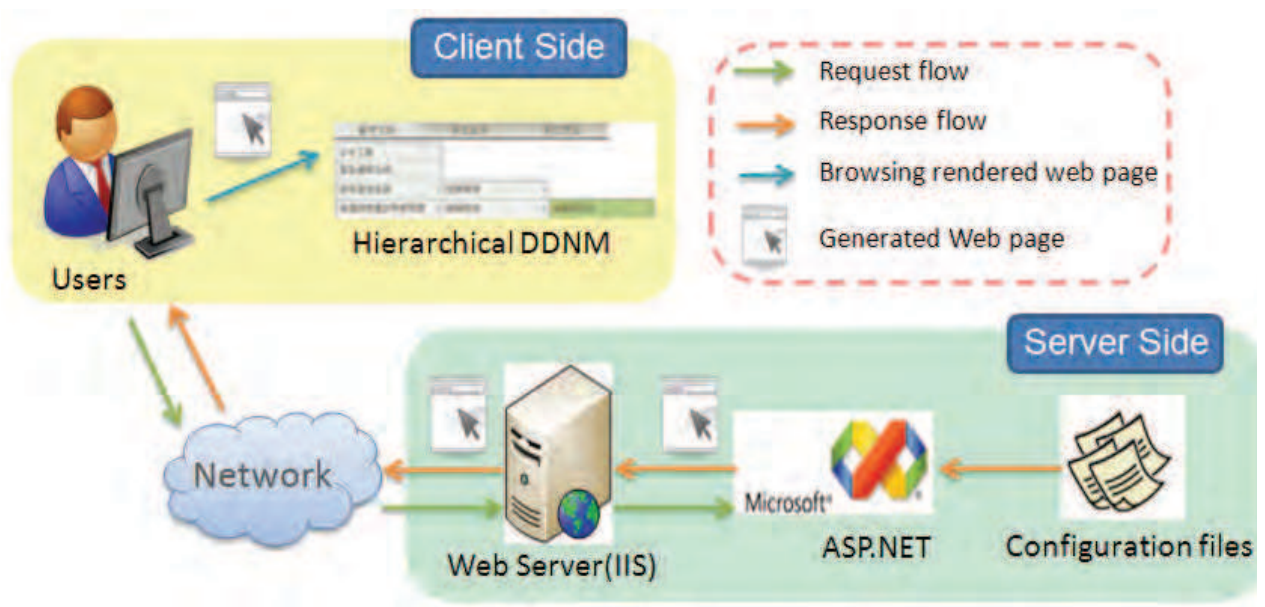

Fig. 4. Concepts of dynamic, hierarchical DDNM

\subsubsection{Content of configuration file}

While generating the portal main page, the server side programs retrieve properties from configuration files. In the file, it contains parameters: access control capabilities, linkage modes and multi-server redirections, as well as target control.

The configuration files have been categorized into 7 groups. Thus, there are 7 configuration files initially. Because the portal needs to redirect to servers of development, test, or on-line production environment, we create the corresponding configuration files. The additional configuration files can be introduced as needed later. The XML formatted configuration file is chosen to facilitate the NTUH portal. The detailed attributes with their associated values in configuration files, listed clearly in Table 1, are illustrated as the following:

(a) Access control capability: In the configuration file, the check property defines menu selection visibility. Multiple values can assign to the property as a concatenate string delimited by space. For example, the check value: "report showTestENV MIS" indicates a URL link needs to satisfy three criteria to enable the menu visibility. The user must have the 
report viewing (report) and system developer (MIS) authorities as well as locate in the test environment (showTestENV). Any failure of the checked value will result in the URL link menu not visible.

\begin{tabular}{|c|c|c|}
\hline \multicolumn{3}{|c|}{ 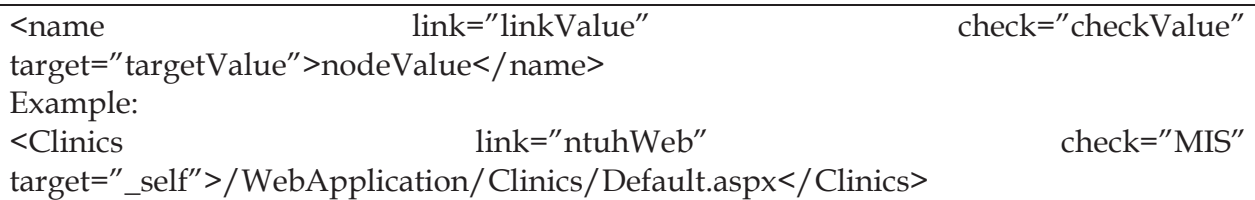 } \\
\hline $\begin{array}{l}\text { Node or } \\
\text { property }\end{array}$ & Value & Description \\
\hline Name & & $\begin{array}{l}\text { Node name. It is the text of menu shown on } \\
\text { web page }\end{array}$ \\
\hline Link & & $\begin{array}{l}\text { Link mode. It indicates how to manipulate the } \\
\text { URL link and includes server redirection. }\end{array}$ \\
\hline \multirow[t]{9}{*}{ linkValue } & adminWeb & $\begin{array}{l}\text { Administration web application: the URL of } \\
\text { administration server appends with the web } \\
\text { page URL, retrieved from nodeValue, to } \\
\text { generate a full web URL. }\end{array}$ \\
\hline & inpatWeb & $\begin{array}{l}\text { Inpatient web application: the URL of inpatient } \\
\text { server appends with the web page URL, } \\
\text { retrieved from nodeValue, to generate a full } \\
\text { web URL. }\end{array}$ \\
\hline & outpatWeb & $\begin{array}{l}\text { Outpatient web application: the URL of } \\
\text { outpatient server concatenates with the web } \\
\text { page URL, retrieved from nodeValue, to } \\
\text { generate a full web URL. }\end{array}$ \\
\hline & outpatWebWithID & $\begin{array}{l}\text { The URL of outpatWeb appends with the user } \\
\text { login ID. }\end{array}$ \\
\hline & reportLink & $\begin{array}{l}\text { Reporting web application. The URL of } \\
\text { reporting server appends with the web page } \\
\text { URL, retrieved from nodeValue, to generate a } \\
\text { full web URL. }\end{array}$ \\
\hline & staticLink & $\begin{array}{l}\text { Output the nodeValue directly as the target } \\
\text { URL. }\end{array}$ \\
\hline & staticWithID & $\begin{array}{l}\text { The nodeValue attaches the user login ID as the } \\
\text { target URL }\end{array}$ \\
\hline & staticWithKey & $\begin{array}{l}\text { The nodeValue appends the access key as the } \\
\text { target URL }\end{array}$ \\
\hline & staticWithKeyAndID & $\begin{array}{l}\text { The nodeValue concatenates with the access } \\
\text { key and user login ID as the target URL }\end{array}$ \\
\hline Check & & Access control by login ID \\
\hline \multirow[t]{3}{*}{ checkValue } & MIS & Check if the login ID belongs to the role of MIS \\
\hline & GSMMaintain & $\begin{array}{l}\text { Check if the login ID has the right to maintain } \\
\text { GSM cell phone table }\end{array}$ \\
\hline & report & Check if the login ID has the right to access the \\
\hline
\end{tabular}




\begin{tabular}{|l|l|l|}
\hline \multirow{2}{*}{} & & reports of patients \\
\cline { 2 - 3 } & shownTestENV & $\begin{array}{l}\text { Check if the login ID has the right to access the } \\
\text { testing environment. }\end{array}$ \\
\cline { 2 - 3 } & qResult & $\begin{array}{l}\text { Check if the login ID has the right to access the } \\
\text { questionary results }\end{array}$ \\
\hline Target & $\begin{array}{l}\text { Target control. It indicates how to open the web } \\
\text { page with browser }\end{array}$ \\
\cline { 2 - 3 } & _self & Open a new page in the original browser \\
\hline nodeValue & & $\begin{array}{l}\text { Open a new page in a newly created browser } \\
\text { needs to be translated }\end{array}$ \\
\hline
\end{tabular}

Table 1. The properties of a configuration file

(b) Linkage modes and multi-server redirections: the link property controls the URL link generation. For example, the link property can assign outpatWeb, inpatWeb, ssoLink, or reportLink as value. The outpatWeb indicates the application linkage redirects to Outpatient Information System servers. Similarly, the inpatWeb redirects to Inpatient Information System servers. The ssoLink integrates SSOS for NTUH multi-system validation, especially in non ASP.NET server environment. Finally, the reportLink enables Medical Report Review Services. In addition, HIS provides multi-environment, as mentioned in the "Redirect scheme" Section, to perform the complete execution environment. The link property also controls the multi-server redirections for HIS multi-environment.

(c) Target control: This control has the same meaning as HTML target property. Target property controls where the new web page will be displayed when a user follows a link. In the configuration file, target property maintains the target control.

\subsubsection{A case study}

Figure 5 shows a brief scenario. Initially, a user logs into the on-line production portal. After selecting the target menu group, i.e., HIS (as described in 4.3.1), the portal server will parse the HIS configuration file, as enclosed in the upper rectangular block of Figure 5, to generate the linkage web URLs. In the group, there are two menus: OutPatientSystem and InPatientSystem. PatientRegistration, Clinics, and Billing are the sub-menus of OutPatientSystem. In Clinics and Billing, there are two access capabilities which are kept in the check property: MIS and showTestENV (indicated in the pink boxes). If a user cannot pass either of the two checks, these menus will not be visible on the web page, as depicted at the right hand side of menu selections. On the other hand, when a user passes both checks of MIS and shownTestENV, the result is shown as the left hand side of menu selections. The menu selections are visible to the user. The menu, in green, means it is active. When it is active, one click will trigger the redirection to the menu's web URL.

A medical staff logs onto the PatientRegistration of the Outpatient Information System (OIS) under the on-line production environment as indicated in the middle part of Figure 5. The link property has outpatWeb as its value. Based on the value, the Portal Service retrieves the OIS server URL, http://online.outpat.ntuh.gov.tw, concatenates it with the PatientRegistration default page, /WebApplication/Clinics/Default.aspx, and constructs the OIS PatientRegistration URL. Finally, the user access key, provided by Auth-WS, is appended at the end of PatientRegistration web URL, indicated at the bottom of Figure 5. 
The last property is target control. The value "_self" means that the linked web page will be displayed in the same browser window and our design default value is "_blank", i.e., displaying in a new browser window. Therefore, the approach enables menu navigation accurately and timely.

\subsubsection{DDNMLog Scheme}

The design criteria of the newly NTUH HIS logging system can be defined as: 1) To provide an application framework for logging website usages with a caching and database approach; 2) Not to interfere with normal NTUH HIS Web operation traffics or performances. In the DDNM portal, in order to keep the favourite links for the NTUH users, we can log users' behaviour, DDNMLog, and obtain users popular function links accessed by adapting LRU (Least Recent Used) algorithm. These links will be collected and implemented as "my favourite". Therefore, users can quickly retrieve the links they frequently select. In addition, the pre-fetched links can be cached in advance to improve navigating performance.

DDNMLog, as depicted in Figure 6, allows NTUH HIS website administrators to record and analyze clinician usages of HIS online resources. The application includes four components: Favourite Links Generation, Logging, Queuing \& Caching, and Back-end HIS Database. Favourite Links Generation and Logging components are embedded in NTUH portal. The other components are integrated in NTUH HIS .NET environment.

In the diagram, the Auth-WS validates user's authentication, authorization and generates an access key for the user. DDNMLog recognizes the same individual no matter where he/she might be located in office, in lab, at home (via NTUH Virtual Private Network), or behind the NTUH Intranet. To facilitate and expedite the clinician operations, the Favourite Links Generation Module constructs and extracts the most recently executed function linkages retrieved (via .Net Remoting technique) from the FavouriteTable, implemented as .NET DataTable, in Queuing \& Caching Module. The Module is implemented as a daemon, i.e., Window Service, resided in Portal Server.

The DDNMLog presents a caching and database approach implemented as an embeddable, plug-in, service, invoked by the medical practitioners. The FavouriteTable is periodically restored into the HIS Database for synchronization. The table is solely pre-fetched from the Database by the daemon, i.e., Queuing \& Caching Module, after each re-start. Under normal operations, the daemon re-start rarely happens.

The DDNMLog database schema is described as followings. The MyFavouriteTable, in HIS Database, consists of 4 attributes: 1) ID (User ID); 2) LinkItemNum (function linkage number); 3) AccessTime (function linkage access timestamp); 4) Rank (LRU priority based on 3). The FavouriteTable attributes, in Queuing \& Caching Module, are matched with the MyFavouriteTable attributes correspondingly. 

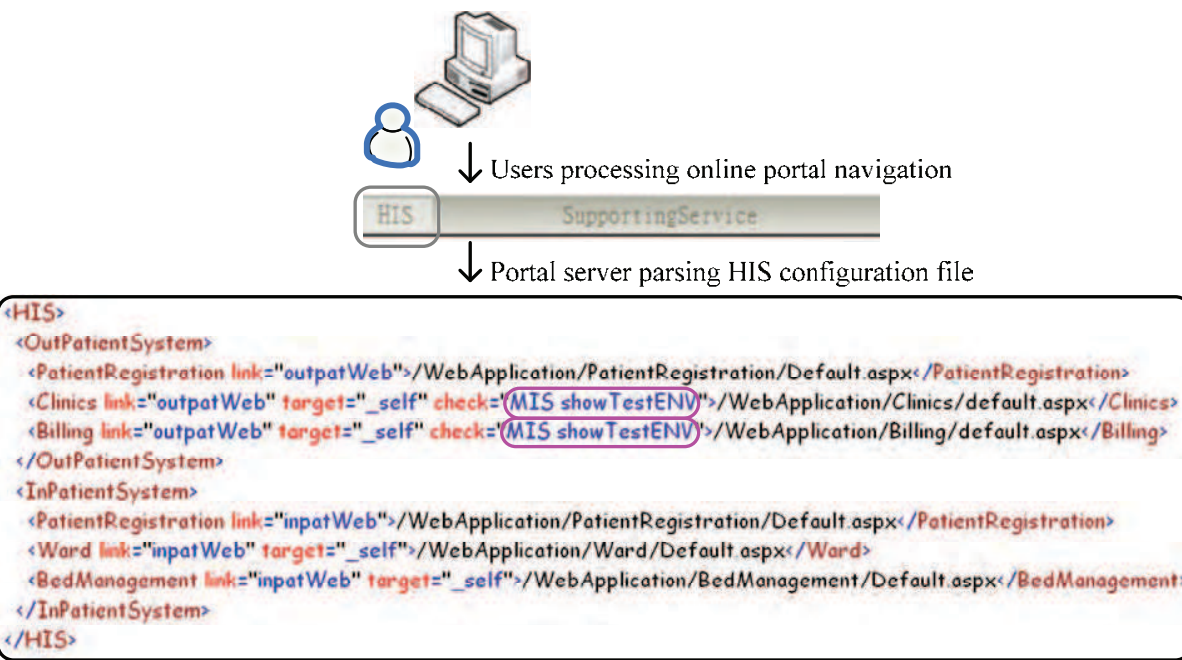

While the user succeeding to pass

" MIS" \& " showTestENV"<smiles>C1CCCCC1</smiles>

HIS 1 SupportingService

While the user failing to pass "MIS" or " showTestENV" check

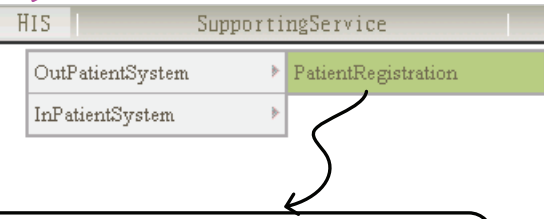

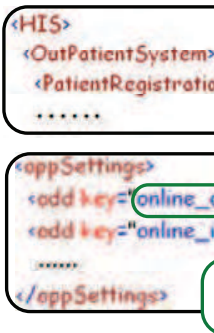

Personal 256bit authorization information: SESSION=68843D98D26CC62B2CB24BD09267IF38 $\longrightarrow$ $\downarrow$ Linkage URL

PatientRegistration complete linkage:

http:/online.outpat.ntuh.gov.tw/WebApplication/PatientRegistration/Default.aspx?SESSION=68843D98D26CC62B2CB24BD09267/F38

Fig. 5. An example of dynamic, hierarchical DDNM 


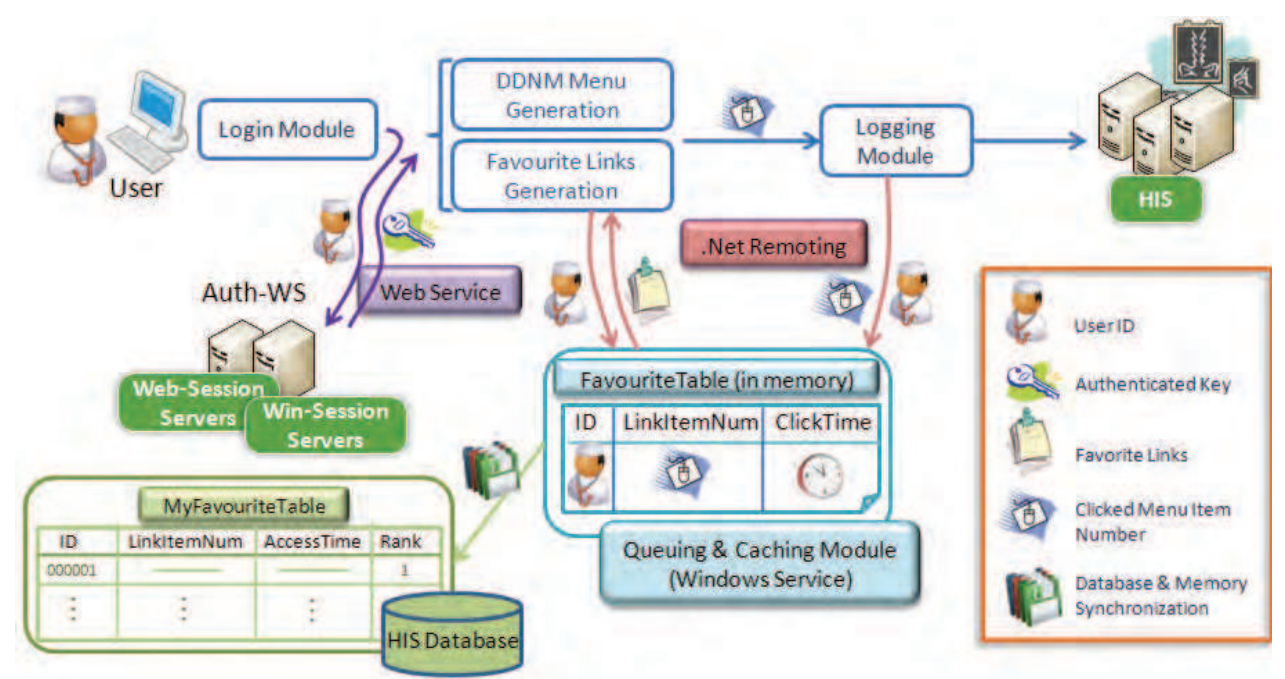

Fig. 6. Concepts of DDNMLog

\subsubsection{Additional tools}

There are two bulletins in NTUH, administrative and system bulletins. The administrative bulletin focuses on NTUH news, announcements; the system bulletin addresses HIS maintenance. Two bulletins need to be rendered within a web page margin. In addition, the bulletins require supporting the on-line modification features. The NTUH system administrator can insert, delete, and update the bulletins frequently in real time. Any alternation of the bulletins ought to be logged into a database promptly. When a user enters into the portal, the main page will dynamically, immediately retrieve information from the database and display on the page.

Moreover, the portal provides two tools: site map and download template. The site map is generated automatically, accordingly by the portal configuration files. The map will be updated while the portal is being altered. When a user activates the site map function, the map can be spontaneously regenerated based upon the newly configured features stored in the configuration files. In other words, the site map is maintained correspondingly by the portal configuration files. The function supports "shortcuts" to improve linkage targets searching temporally and spatially. Furthermore, the administrator can utilize the template, created from a web page, in order to construct the download page to announce special issues, meeting memorandums, etc. uploaded as files in NTUH. 


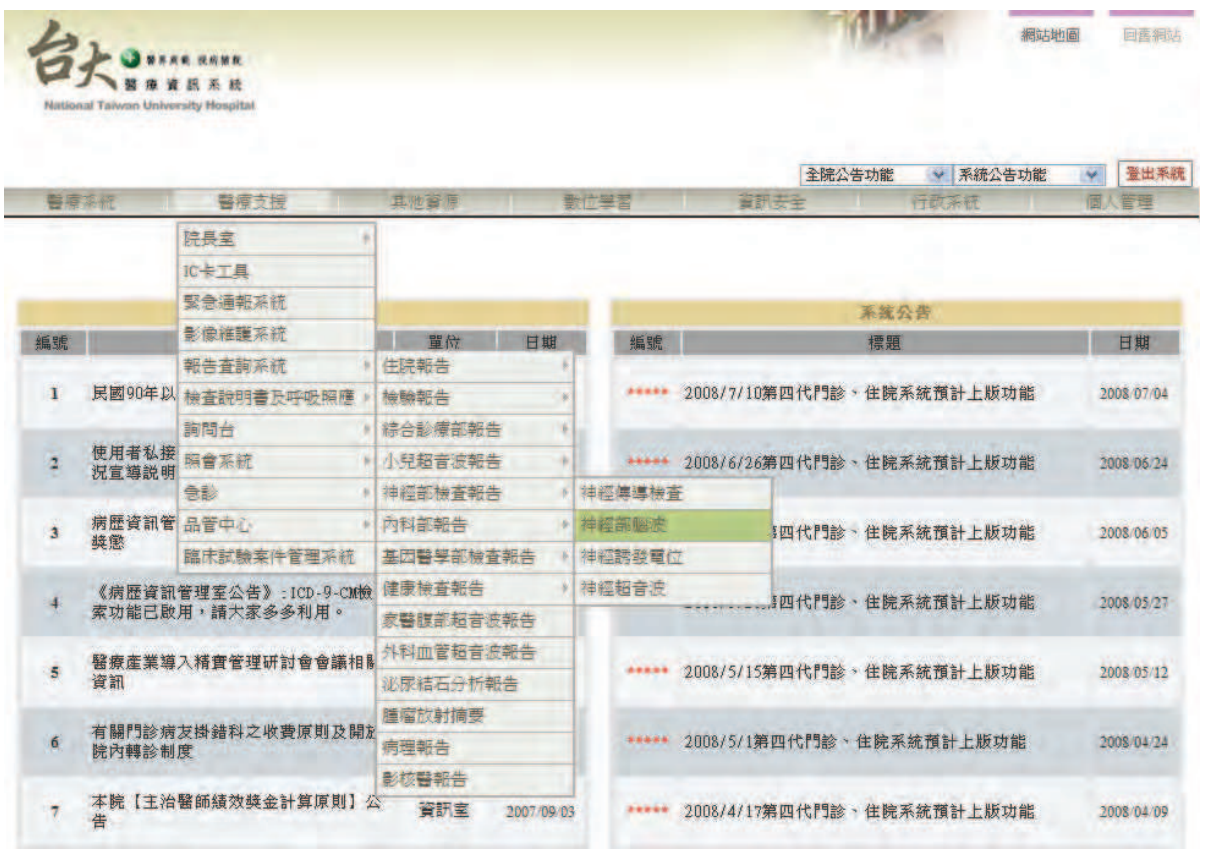

Fig. 7. The new portal contains two bulletins and over 300 function linkages classified in groups

\section{Achievements \& performance evaluation}

\subsection{Achievements}

The new portal has been operating on-line since June 2006 (as shown in Figure 7). The portal provides the front end integration for NTUH numerous systems by implementing the SSOS strategy. In the diagram, for menu selections, well organized classifications as well as grouping make the user navigate intuitively. The usage of dynamic, hierarchical DDNM reduces menu clicks and prevents the menu bar scrolling. In addition, it is easier to spontaneously maintain the URL links by simply managing the configuration files.

The portal implementation raises a performance issue. In the first version of DDNM, it generates all function linkages every time (about 300). The server side program needs to parse all configuration files as well as create all HTML and JavaScript codes. It takes about 10 seconds on average to display the portal main page. In order to solve the issue, the DDNM second version has been designed and implemented by classified groups. The server side program only needs to process the selected group configuration file each time. Under the most complicated group, it takes approximately 2 seconds, on average, to render the main page.

\subsection{Performance evaluations}

In the NTUH HIS, the Portal Servers construct dynamic web URL linkages and front end requests to HIS components. The Auth-WS validates user's authentication as well as 
authorization. The Portal Servers and the Auth-WS act critical roles for NTUH HIS front end performance. Therefore, we evaluate and analyze these two components respectively in the architecture.

The Portal Servers, Auth-WS CPU and memory usages, as well as the number of connections collected in a week, 04/13 04/19/2009, aggregated by hours daily. The Portal Servers CPU and memory usages, as well as the number of connections data collected are

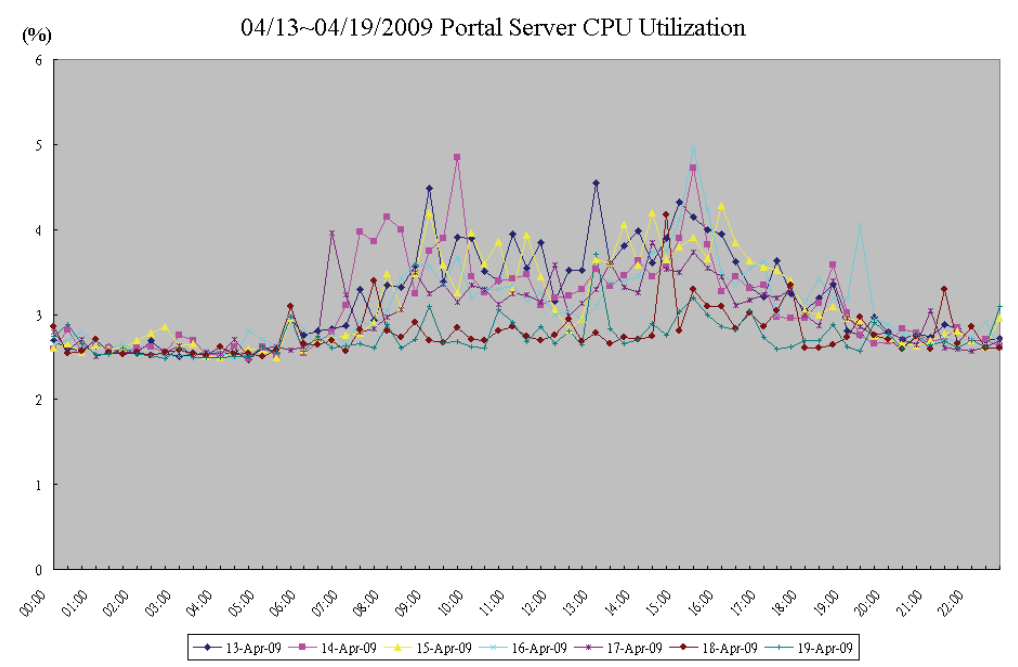

Fig. 8. CPU utilization of the Portal Server

illustrated in Figures 8, 9, and 10 respectively. During the period, on average, the Portal Servers CPU usage reaches $5 \%$ at most diurnally. The memory utilization is under $23 \%$ (on average, it reaches $700 \mathrm{MB}$ approximately with total memory $3 \mathrm{~GB}$ ) and remains steady daily. The number of concurrent connections peaks in the morning and early afternoon during the hospital operational hours. In addition, the numbers fluctuate between 8:00 am and 5:00 pm. The Auth-WS contains the Web-session Servers and Win-session Servers. The Web-session and Win-session Servers CPU, memory usages, as well as the number of concurrent connections are shown in Figures 11-15 respectively. The Win-session Servers are daemons, 


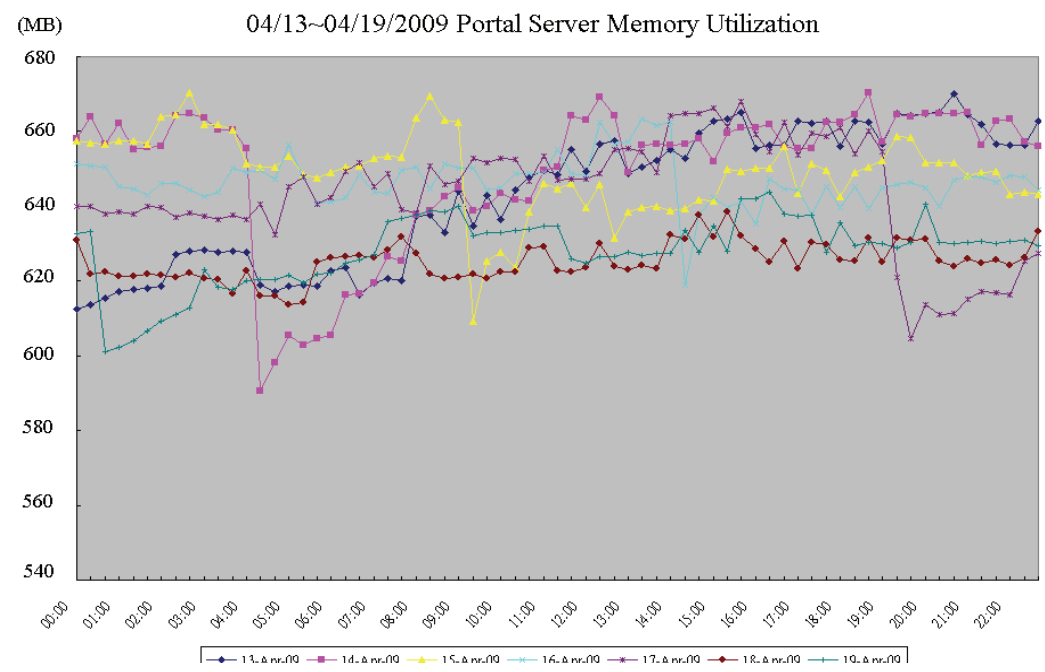

Fig. 9. Memory utilization of the Portal Server

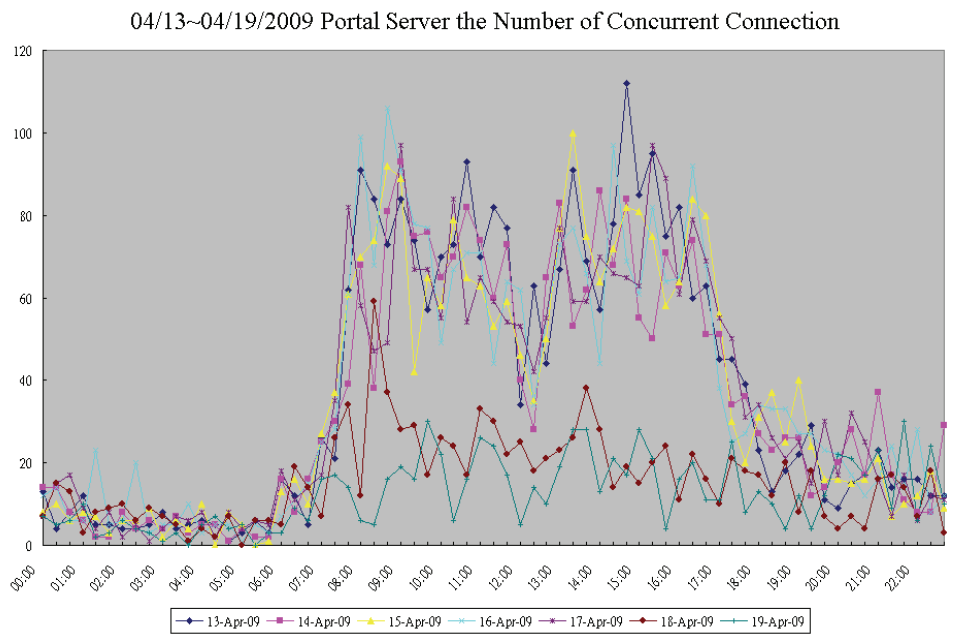

Fig. 10. The number of concurrent connections of the Portal Web Server

not web servers; the number of concurrent connections is not available. During the period, on average, the Web-session Servers and the Win-session Servers CPU usages reach 35\% at most diurnally as indicated in Figures 11 and 14. The usages drop during the lunch break. In Web-session Servers, the memory utilization is under 21\% (on average, it reaches $630 \mathrm{MB}$ approximately with total memory 3GB) and remains steady daily as presented in Figure 12. 


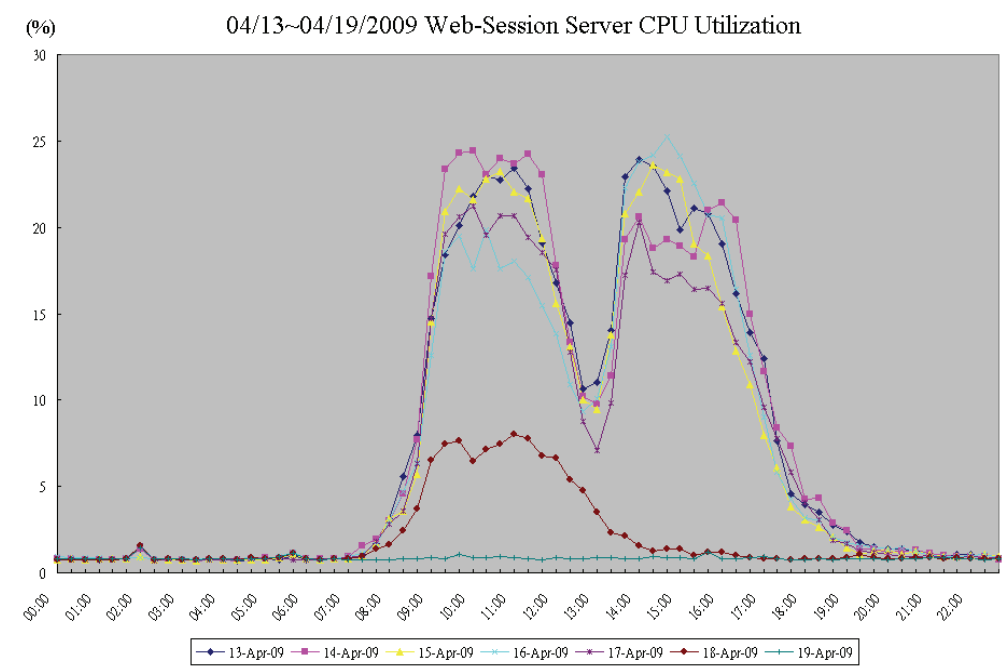

Fig. 11. CPU utilization of the Web-session Server

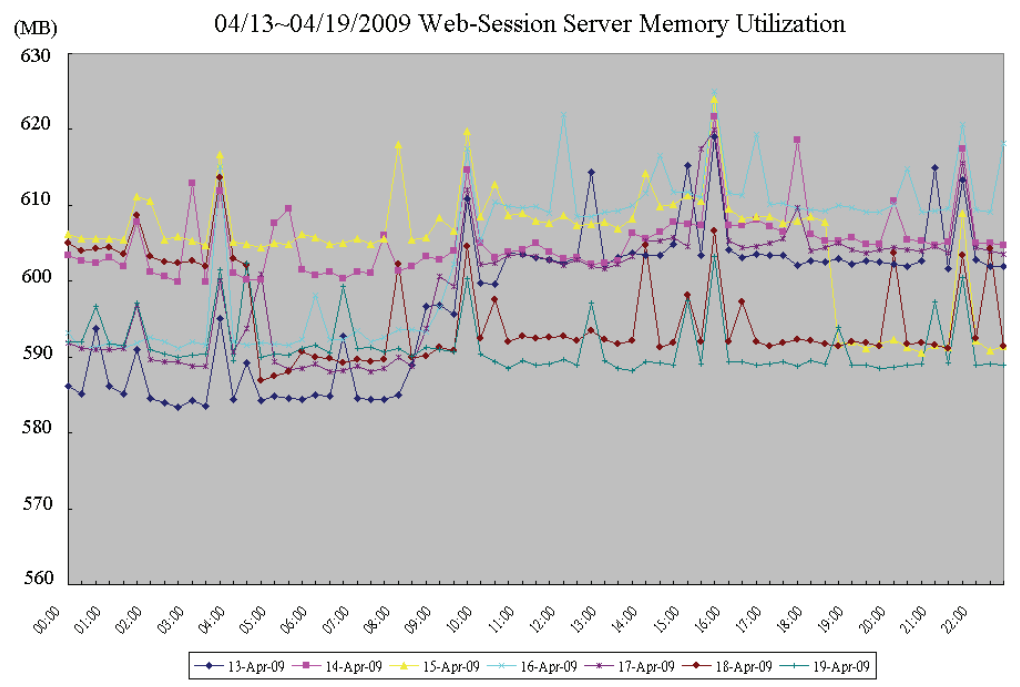

Fig. 12. Memory utilization of the Web-session Server

However, in Win-session Servers the utilization is around 50\% daily as shown in Figure 15. The peaks, indicated in Figure 15, result in the synchronization of authentication and authorization data between the Win-Session Servers and HIS database on hourly basis. 
In general, Figures 8-15, the CPU, memory usages, and the number of concurrent connections in Servers fluctuate steadily between 8:00 am and 5:00 pm over the hospital regular hours from Monday thru Friday (4/13 4/17/2009); the usages drop significantly

04/13 04/19/2009 Web-Session Server the Number of Concurrent Connection

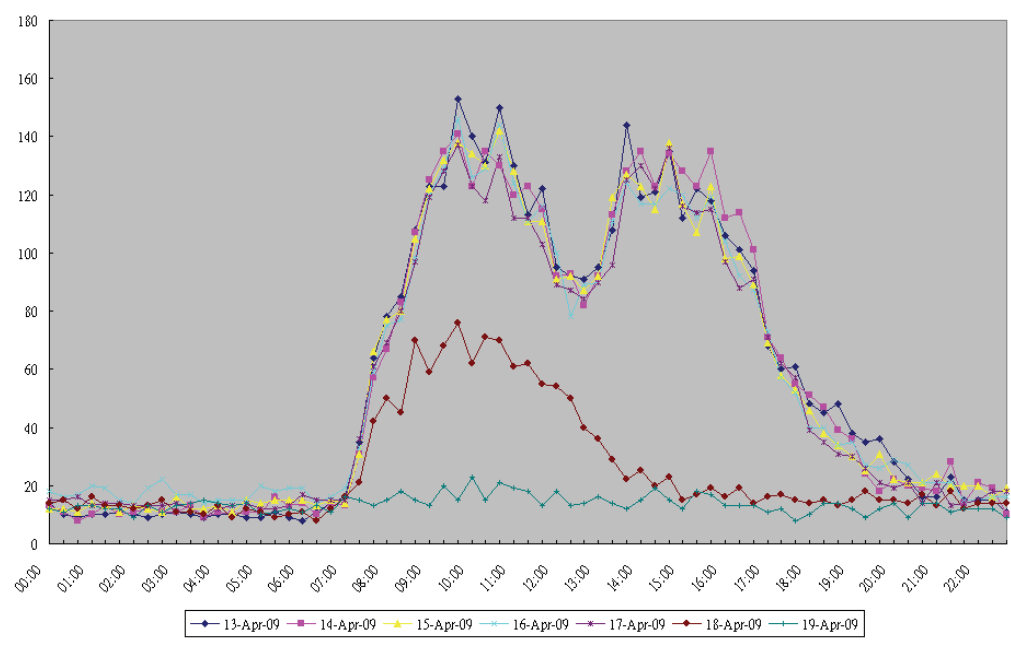

Fig. 13. The number of concurrent connections of the Web-session Web Server

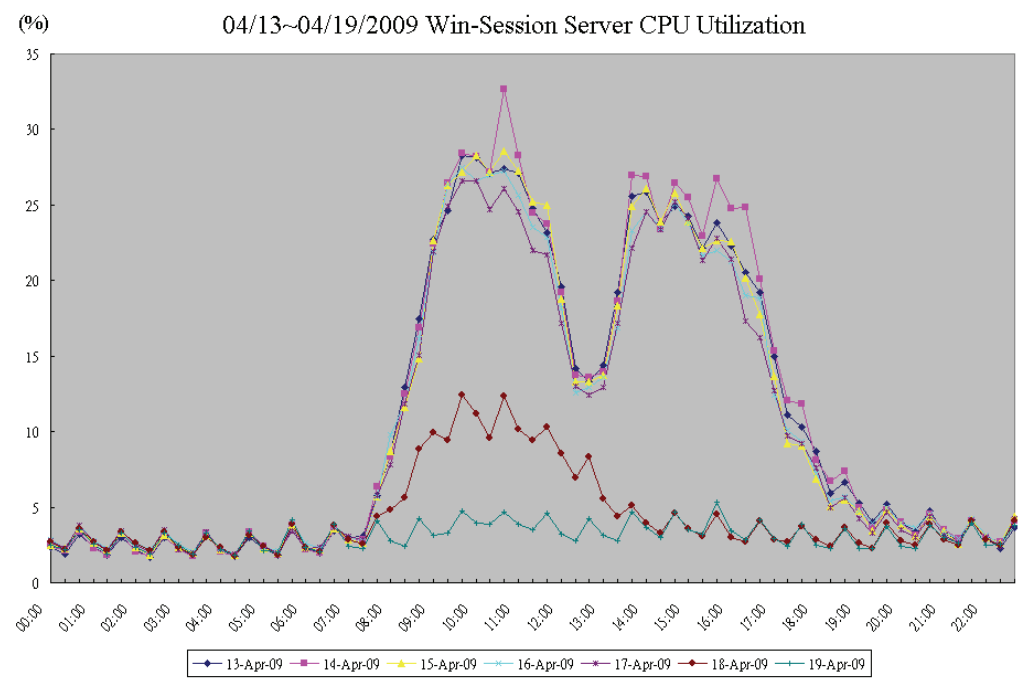

Fig. 14. CPU utilization of the Win-session Server

during the lunch break. On Saturday $(4 / 18 / 2009$, as indicated in the dark brown dashed line), the regular hours for outpatient services are 8:00 am to noon; on Sunday (4/19/2009, 
as indicated in the dark green dashed line), the hospital is closed for outpatient registrations and services. The corresponding usage statistics are presented in the diagrams.

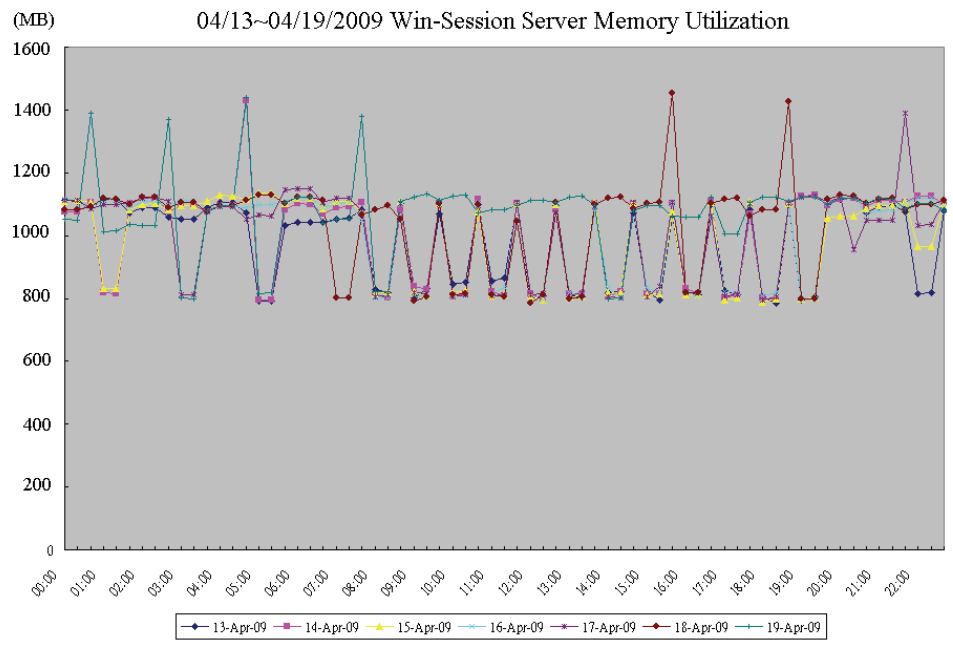

Fig. 15. Memory utilization of the Win-session Server

\section{Discussion}

The NTUH new portal has classified the linkages into groups; the users can operate the portal intuitively and effectively. The portal permits searching by browsing hierarchical classifications of the web-based information. Although there are many positive feedbacks, a beginner is not familiar with the portal layouts initially and may not navigate them smoothly. There is one issue users complain. In general, a user accesses not more than 10 function selections on average. However, in the current design, the user needs to select the target menu from classified groups covering over 300 linkages. It is still time consuming. Regarding the issue, we plan to improve it according to the following approaches:

1) Keeping the favourite links for users: we can log (Liu et al., 2006) users' behaviour and obtain users popular function links by adapting LRU (Least Recent Used) algorithm. These links will be collected and implemented as "my favourite". Users can quickly retrieve the links they frequently execute. In addition, the pre-fetched links can be cached in advance to improve performance. Therefore, an embedded DDNMLog has been implemented in conjunction with NTUH HIS. The application uses Oracle as the back-end log database and is integrated in Microsoft .NET environment. In addition, the application has been pilot since April, 2009.

2) Providing site map facilities: the portal site map can improve targets searching temporally and spatially. The site map is generated, maintained automatically, accordingly by the portal configuration files. The approach illustrates the flexibility of the site map maintenance. NTUH HIS Portal provides medical practitioners and staff with a visible site map to encourage them to navigate the Portal via shortcuts. However, the current NTUH site map is a heavily hierarchical interlinked tree structures; it can induce disorientations (Dieberger, 
1997). On the other hand, the practitioners have different expectations and preferences while navigating the web site to perform their daily operations. It is desirable to ameliorate the situation. Therefore, we propose a technique by utilizing the DDNMLog scheme to retrieve users' behaviours in order to construct a multi-granular, topic of interests site map imposed, derived via the configuration files automatically. The link structures of the map can be presented, indicated by citation analyses with further pruning as well. It is anticipated that the usability effects of the NTUH Portal site map can be improved.

3) Full text searching: the portal will provide the feature. The planned searching engine will examine all the words in bulletin contents, documents, announcements, as well as menus to expedite searching and text retrieval.

4) Customized portal per user: the portal can be customized by per user basis including groups, function links, as well as web page layouts. The approach can be achieved using Web 2.0-based technologies (Knights., 2007; Schroth \& Janner, 2007). The techniques empower users to customize their experiences more effectively than ever before, and share information in more efficient and collaborative way.

Therefore, the combination of these techniques effectively benefits the entire NTUH HIS systems workloads. The portal has been on-line formally since June 2006. The portal provides services for doctors, medical staffs, as well as administrative personnel. In order to understand and validate the perfectionism, completeness of the portal, we conduct periodically assessment interrogation, interviewing, and debriefing to obtain the portal usages, suggestions from the associates for further enhancements as well.

\section{Conclusion}

The NTUH new portal explores the dynamic, hierarchical drop-down navigation menu to visualize function linkages by simply managing the configuration files. The DDNM rendering is flexible for space usage and enlarges the capacity of URL links. It leads the portal contain over 300 function links as well as two bulletins in one web page. The XML formatted configuration files are designed to automate function linkages with access control, linkage modes and multi-server redirections, as well as target control. The new portal generates the main page effectively and efficiently. In addition, the portal supports front end integration for NTUH numerous systems, platforms applying the SSOS scheme. Therefore, the portal provides a unique entrance for NTUH HIS infrastructure. The infrastructure supports the availability of any data, at any time, from any place dynamically.

The NTUH HIS has been developed from the ground up to be an available, robust, reliable, secure, interoperable, and service-oriented architecture. Moreover, the NTUH HIS is an innovation designed to address the continuously changing and demanding natures of today's healthcare environment in Taiwan. It presents a solution to perform challenges imposed by heavy messaging traffic that is threatening the viability of Web-Services (.NET) implementations. As a result, capital expenditures are controlled and the return on investment is shorter.

In summary, the NTUH HIS portal is a vehicle driven to support integrated access to information needed by Hospital constituents, whether they are students, staff, or faculty. Furthermore, the additional tools, techniques empower medical practitioners to customize, fulfil their experiences more comprehensively. The DDNMLog service provides a dynamic function linkage usages monitoring and allows just-in-time (shortcuts) accesses for users. On 
the other hand, NTUH HIS Portal is a large, complicated, heavily interlinked web site; it is likely to be disoriented. However, the Portal is a visible, hierarchical tree topology, and immediately accessible; under the circumstances, the site map is significantly accommodating (Yip, 2004; Danielson, 2002). As the portal continues to be developed and enhanced, the new features can be added on a regular basis.

The aspects of the NTUH Portal accessibility, i.e., visual structure, colour contrast, and text size, in compliance with Web Content Accessibility Guidelines 2.0 (WCAG 2.0, 2008), are under preliminary investigation.

\section{References}

Adabala, S.; Matsunaga, A.; Tsugawa, M.; Figueiredo, R. \& Fortes, J.A.B. (2004). Single SignOn in In-VIGO: Role-based Access via Delegation Mechanisms Using Short-lived User Identities, Proceedings of the 18th Parallel and Distributed Processing Symposium, pp. 22

Adamcik, B.A.; Ransford, H.E.; Oppenheimer, P.R.; Brown, J.F.; Eagan, P.A. \& Weissman, F.G. (1986). New clinical roles for pharmacists: a study of role expansion, Soc Sci Med.,23(11):1187-200

Amor, D. (1999). E-business Revolution, Hewlett-Packard Books, pp. 220 - 221

Anamarija, R.H. ; Dimitar, H. \& Ljupco, T. (2002). Users' information-seeking behavior on a medical library website, J Med Libr Assoc, 90:210 -7

Arbor, A. (2000). Health Level 7, HL7 Version 3.0., MI: HL7, 2000

[Online]: http://www.hl7.org (Accessed: 18 June 2009)

Azar, S.N. ; Jalali, A.H. \& Falsafi, S. (2008). Commercial Portals Evaluation, Advanced Communication Technology, ICACT 2008, 10th International Conference, pp. 2035 - 2039

Barkley, J. (1997). Comparing Simple Role Based Access Control Models and Access Control Lists, Proceedings of the Second ACM Workshop on Role Based Access Control, pp. 127132

Bernard, M. (1999). Findings on the use of sitemap.

[Online]: http://psychology.wichita.edu/surl/Sitemap.html (Accessed: 6 Mar 2003).

Bracke, P.J. (2002). Web usage mining at an academic health sciences library: an exploratory study, J Med Libr Assoc, 92:421-8

Brakel, Pieter van (2003). Campus Portals for content: the next generation of academic Websites?, 5th Annual Conference on World Wide Web Applications

Bullough, B. (1976). Influences on Role Expansion, the American Journal of Nursing, Vol. 76, No. 9, pp. 1476-1481

Bunge, R., Chung, S. \& Endicott-Popovsky et al. (2008). An Operational Framework for Service Oriented Architecture Network Security, Hawaii International Conference on System Sciences, Proceedings of the 41st Annual, pp. 312 - 312

Chen, E.S. \& Cimino, J.J. (2003). Automated discovery of patient-specific clinician information needs using clinical information system log files, AMIA Annu Symp Proc. 2003,pp. 145-149

Chen, E.S. \& Cimino, J.J. (2004). Patterns of usage for a Web-based clinical information system. Med Inform, pp. 18 -22. 
Cheng, P.H. ; Yang, T.H. ; Chen, H.S. ; Hsu, K.P. ; Chen, S.J. \& Lai, J.S. (2004). Codesign of a Healthcare Enterprise Information Portal and Hospital Information Systems, in Plastics, 2nd ed. vol. 3, J. Peters, Ed. New York: McGraw-Hill, pp. 15-64

Danielson, D.R. (2002). Web navigation and the behavioral effects of constantly visible site maps. Interacting with Computers, 14 (5), October 2002, pp. 601-618

Dieberger, A. (1997). A city metaphor to support navigation in complex information spaces. Spatial Information Theory: a Theoretical Basic for Gis, 1329, 67

Farkas, D. K. \& Farkas, J. B. (2000). Guidelines for designing web navigation. Technical Communication, Third Quarter, pp. 341-358

Fraser, H.S.F. ; Kohane, I.S. \& Long, W.J. (1997). Using the Technology of the Would Wide Web to Manage Clinical Information, BMJ, 314: pp. 1600-1603

Freudenstein, P.; Nussbaumer, M. ; Majer, F. \& Gaedke, M. (2007). A Workflow-Driven Approach for the Efficient Integration of Web Services in Portals, Services Computing, SCC 2007, IEEE International Conference, pp. 410 - 417

Goodman, D. (2003). JavaScript \& DHTML Cookbook, O’Reilly

Heckle, R. (2007). Individual authentication in a collaborative environment: lessons from a single sign-on implementation, Conference on Supporting Group Work, Group '07 Doctoral Consortium papers, Article No. 3

Heckle, R.; Lutters, W.G. \& Gurzick, D. (2008). Network authentication using single sign-on: the challenge of aligning mental models, Proceedings of the 2nd ACM Symposium on Computer Human Interaction for Management of Information Technology, SESSION: Security, Article No. 6

HL7 Standard v2.5 (2003), Health Level Seven (HL7), Chapter 4, pp. 4-14 - 4-17

Hsieh, S.H. ; Hsieh, S.L. ; Weng, Y.C. ; Yang, T.H. ; Lai, Feipei \& Cheng, P.H. et al. (2007). Middleware based Inpatient Healthcare Information System, Bioinformatics and Bioengineering, BIBE 2007, Proceedings of the 7th IEEE International Conference, pp. $1230-1234$

Hsieh, S.L.; Lai, F.; Cheng, P.H.; Chen, J.L.; Lee, H.H. \& Tsai, W.N. et al. (2006). An Integrated Healthcare Enterprise Information Portal and Healthcare Information System Framework, IEEE EMBC 2006, pp. 4731-4734

Inder, R. ; Kilgour, J. \& Lee, J. (1998). Automatic generation of diagrammatic Web site maps, Proceedings of the 1998 ACM symposium on Applied Computing, pp. 719-725

Kim, H. \& Hirtle, S. (1995). Spatial metaphors and disorientation in hypertext browsing. Behaviour \& Information Technology, 14(4), 239-250

Ko, L.F. ; Lin, J.C. ; Chen, C.H. ; Chang, J.S. ; Lai, Feipei \& Hsu, K.P. et al. (2006). HL7 middleware framework for healthcare information system, e-Health Networking, Applications and Services, HEALTHCOM 2006, pp. 152-156

Lee, W.B. ; Min, S.D. ; Jeong, W. ; Choo, Y. \& Lee, M. (2007). Construction of APEC e-Health Portal Site for e-Health Service Providers and Demanders in APEC area. e-Health Networking, Application and Services, 2007 9th International Conference, pp. 300 - 303

Lewis, G.A. ; Morris, E. ; Simanta, S. \& Wrage, L. et al. (2007). Common Misconceptions about Service-Oriented Architecture, Commercial-off-the-Shelf (COTS)-Based Software Systems, ICCBSS '07, Sixth International IEEE Conference, pp. 123 - 130

Li, W.S. ; Ayan, N.F. ; Kolak, O. ; Vu, Q. ; Takano, H. \& Shimamura, H. (2001). Constructing Multi-Granular and Topic-Focused Web Site Maps, Proceedings of the 10th international conference on World Wide Web, pp. 343 - 354 
Liu, N.; Marenco, L. \& Miller, P.L. (2006). ResourceLog: An Embeddable Tool for Dynamically Monitoring the Usage of Web-Based Bioscience Resources, J. Am. Med. Inform. Assoc. 2006, 13(4): pp. 432-437; doi:10.1197/jamia.M2013

Mary, D. (2002). Portal Project Overview, Washington State University, [online] Available: http://www.wsu.edu/portal-project/background.html

Mauro, C.; Sunyaev, A.; Leimeister, J.M.; Schweiger, A. \& Krcmar, H. (2008). A Proposed Solution for Managing Doctor's Smart Cards in Hospitals Using a Single Sign-On Central Architecture, Proceedings of the Proceedings of the 41st Annual Hawaii International Conference on System Sciences, pp. 256

McDonald, C.J. ; Overhage, J.M. ; Dexter, P.R. ; Blevins, L. ; Johnson, J.M. \& Suico, J.G. et al. (1998). Canopy Computing: Using the Web in Clinical Practice, Journal of the American Medical Association, 280(15): pp. 1325-1329

Murray, M. (2002). An investigation of specifications for migrating to a web portal framework for the dissemination of health information within a public health network, In Proceedings of the 35th Annual Hawaii International Conference on System Sciences, pp. 1917-1925

Murray, M. (2003). Strategies for the successful implementation of workflow systems within healthcare: a cross case comparison, System Sciences, 2003. Proceedings of the 36th Annual Hawaii International Conference, pp. 10

Nielson, J. (2002). Site Map Usability.

[Online]:http:/ / www.useit.com/alertbox/20020106.html (Accessed: 6 Mar 2003)

Knights, M. (2007). Web 2.0, Communications Engineer, Vol. 5, Issue 1, pp. 30 - 35, FebruaryMarch 2007

Krafzig, D., Banke, K. \& Slama, D. (2005). Enterprise SOA: Service Oriented Architecture Best Practices, Prentice-Hall, Englewood Cliffs, 2005

Oo, I. (2006). Presentation Level Integration of Portal Personalization Architecture, Information and Communication Technologies, ICTTA '06. 2nd Volume 1, 24-28, pp. $564-565$

Papazoglou, M.P. (2003). Service -Oriented Computing: Concepts, Characteristics and Directions, Proceedings of the Fourth International Conference on Web Information Systems Engineering, pp. 3

Papazoglou M.P. \& Heuvel, W.J. (2007). Service-Oriented Architectures: Approaches, Technologies and Research Issues, VLDB J., vol. 16, no. 3, 2007, pp. 389-415

Phan, C. ; Lee, L. \& Fleischer, R. (2007). Service Oriented Architecture (SOA) - Security Challenges and Mitigation Strategies, Military Communications Conference, MILCOM 2007, pp $1-7$

Raghupathi, W. (1997). Health Care Information Systems, Comm of the Association for Computing Machinery, 40(8): pp. 81-82

Rosen, M. (2000). Enterprise Portals, Software Magazine, Vol. 20, No. 5, pp. 22 - 25, October 2000

Rozic-Hristovski, A.; Hristovski, D. \& Todorovski, L (2002). Users' information-seeking behavior on a medical library Website, J Med Libr Assoc, 90:210 -7

Rowbottom, N.; Allam, A. \& Lymer, A (2005). An exploration of the potential for studying the usage of investor relations information through the analysis of Web server logs, International Journal of Accounting Information Systems, 6 :31-53 
Rudenstien, R. (2000). A Bright Idea, Enterprise Systems Journal, Vol. 15, No. 1, pp. 24 - 30, January 2000

Russler, D.; Stanic, S. \& Davis, F. (2001). Benefiting from the Evolution towards a Healthcare Adaptive Portal Framework, Proceedings of the 2001 Health Information Systems Society Conference, Vol. 4, February 2001

Schroth, C. \& Janner, T. (2007). Web 2.0 and SOA: Converging Concepts Enabling the Internet of Services, IT Professional, Vol. 9, Issue 3, pp. 36 - 41, May-June 2007

Shepherd, M. ; Zitner, D. \& Watters, C. (2000). Medical portals: Web-based access to medical information, In Proceedings of the 33rd Annual Hawaii International Conference on System Sciences, pp. 1-10

Strauss, H. (2002). All about Web Portals: A Home Page Doth Not a Portal Make, In Web Portals E Higher. Education: Technologies to Make IT Personal, edited by RichardN. Katz. San Francisco: Jossey-Bass

Trippe, B. (2001). Content Management Technology: A Booming Market, Econtent, Vol. 24, No. 1, pp. 22 - 27, February/March 2001

Tsai, C.W. ; Ho, J.H. ; Liang, T.W. \& Yang, C.S. (2005). An intelligent Web portal system for Web information region integration, Systems, Man and Cybernetics, IEEE International Conference, pp. 3878-3883 Vol. 4

Volchkov, A. (2001). Revisiting Single Sign-On: A Pragmatic Approach in a New Context, IT Professional, Volume 3, Issue 1, pp. 39-45

WCAG 2.0, Web Content Accessibility Guidelines 2.0, December 2008 [Online]: http://www.w3.org/TR/WCAG20/ (Accessed: 18 June 2009)

Weng, Y.C. ; Hsieh, S.L. ; Hsieh, S.H. \& Lai, Feipei (2007). Design and Enhance a Dynamic Healthcare Portal Site, Web Intelligence and Intelligent Agent Technology Workshops, 2007 IEEE/WIC/ACM International Conferences, pp. 173 - 176

Woods, N.F. (2007). Women's roles and illness episodes: A prospective study, Research in Nursing $\mathcal{E}$ Health, Volume 3 Issue 4, pp. 137-145

Yang, T.H. ; Cheng, P.H. ; Yang, C.H. ; Lai, Feipei ; Chen, C.L. \& Lee, H.H. et al. (2006). A Scalable Multi-tier Architecture for the National Taiwan University Hospital Information System based on HL7 Standard, Computer-Based Medical Systems, CBMS 2006, 19th IEEE International Symposium, pp. 99 - 104

Yip, A (2004). The effect of different types of site maps on user's performance in an information-searching task, Proceedings of the 13th international World Wide Web conference, pp. 368-369

Zhang, L.; Ahn, G.J. \& Chu, B.T. (2003). A rule-based framework for role-based delegation and revocation, ACM Transactions on Information and System Security (TISSEC), Volume 6 , Issue 3, pp. 404-441

Zhu, F. ; Wang, A. \& Ju, Y. (2004). A framework to develop a university information portal, Information Acquisition 2004 Proceedings, International Conference, pp. 506-509

Zirpins, C. ; Weinreich, H. ; Bartelt, A. \& Lamersdor, W. (2001). Advanced Concepts for Next Generation Portals, 12th International Workshop on Database and Expert Systems Applications, pp. $501-506$ 


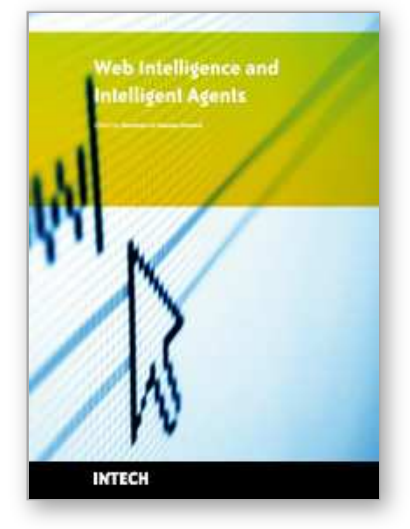

\section{Web Intelligence and Intelligent Agents \\ Edited by Zeeshan-UI-Hassan Usmani}

ISBN 978-953-7619-85-5

Hard cover, 486 pages

Publisher InTech

Published online 01, March, 2010

Published in print edition March, 2010

This book presents a unique and diversified collection of research work ranging from controlling the activities in virtual world to optimization of productivity in games, from collaborative recommendations to populate an open computational environment with autonomous hypothetical reasoning, and from dynamic health portal to measuring information quality, correctness, and readability from the web.

\section{How to reference}

In order to correctly reference this scholarly work, feel free to copy and paste the following:

Yung-Ching Weng, Sheau-Ling Hsieh, Kai-Ping Hsu, Chi-Huang Chen, Po Hsun Cheng and Feipei Lai (2010). A Dynamic Healthcare Portal Design and Enhancements, Web Intelligence and Intelligent Agents, Zeeshan-UIHassan Usmani (Ed.), ISBN: 978-953-7619-85-5, InTech, Available from:

http://www.intechopen.com/books/web-intelligence-and-intelligent-agents/a-dynamic-healthcare-portal-designand-enhancements

\section{INTECH}

open science | open minds

\author{
InTech Europe \\ University Campus STeP Ri \\ Slavka Krautzeka 83/A \\ 51000 Rijeka, Croatia \\ Phone: +385 (51) 770447 \\ Fax: +385 (51) 686166 \\ www.intechopen.com
}

\author{
InTech China \\ Unit 405, Office Block, Hotel Equatorial Shanghai \\ No.65, Yan An Road (West), Shanghai, 200040, China \\ 中国上海市延安西路65号上海国际贵都大饭店办公楼 405 单元 \\ Phone: +86-21-62489820 \\ Fax: $+86-21-62489821$
}


(C) 2010 The Author(s). Licensee IntechOpen. This chapter is distributed under the terms of the Creative Commons Attribution-NonCommercialShareAlike-3.0 License, which permits use, distribution and reproduction for non-commercial purposes, provided the original is properly cited and derivative works building on this content are distributed under the same license. 